\title{
O livro-jogo como recurso didático-pedagógico no desenvolvimento da Educação Matemática Crítica
}

\section{The gamebook as a didactic-pedagogical resource in the development of Critical Mathematical Education}

\author{
Sarafago Pinto Neri (sa rafagoneri@ hotmail) \\ Universidade Federal do Rio Gra nde (FURG), campus Santo Antônio da Patrulha \\ Lucas Nunes Ogliari (luca sogliari@furg.br) \\ Universida de Federal do Rio Grande (FURG), campus Santo Antônio da Patrulha
}

Resumo: O presente relato objetiva apresentar uma experiência com a utilização do livro-jogo como recurso didático-pedagógico no ensino de matemática com o viés da Educação Matemática Crítica (EMC). O livro-jogo foi elaborado a partir do programa Twine 2, plataforma on-line para criação de livros-jogos com a possibilidade de leitura inclusive em smartfone. Intitulado "Uma aventura em Reai\$", o livro foi disponibilizado a uma turma de 20 alunos do Ensino Fundamental de uma escola da rede pública municipal no estado do Rio Grande do Sul. Tendo como objetivo compreender a potencialidade do livro-jogo na construção de cenários para a investigação em Matemática. A aplicação em aula do livro-jogo permitiu coletar dados a partir de observações, questionários, debates e demais produções dos alunos, como cálculos e questionamentos, esses últimos redigidos uma ficha de registro utilizada pelos participantes durante a aplicação da atividade. Dados estes analisados de forma a confrontar a potencialidade do livro-jogo com o desenvolvimento de conceitos da EMC em cenários de investigação propostos no decorrer da atividade. Nas análises iniciais da metodologia desenvolvida, observou-se que o livro-jogo foi estimulante aos alunos por trazer, de uma forma diferente, a abordagem de conhecimentos matemáticos relacionados a vivências diárias, o que proporcionou uma visão mais atenta e crítica sobre estes aspectos.

Palavras-chave: Livro-jogo; Educação Matemática Crítica; Ensino de Matemática.

Abstract: The following article aims to present an experience with the use of the
gamebook as a didactic-pedagogical resource in the teaching of mathematics from the
perspective of Critical Mathematics Education (EMC). The gamebook was developed
using the Twine 2 application, an online platform for creating gamebooks with the
possibility of reading even on a smartphone. Entitled "An adventure in Reai\$", the book
was applied to a group of 20 elementary school students from a public school in the
state of Rio Grande do Sul. With the objective of verifying the potential of the

Recebido em: 30 /04/ 2020

Aceito em: 19/11/2020 
gamebook in the construction of scenarios for research in mathematics. The application in class of the gamebook allowed the collection of data from observations, questionnaires, debates and other productions of the students, such as calculations and questions written in a diary used by the participants during the application of the activity. These data were analyzed to confront the potential of the gamebook with the development of EMC concepts in research scenarios proposed during the activity. In the initial analyzes of the developed methodology, it was observed that the gamebook was stimulating to the students for bringing, in a different way, the approach of mathematical knowledge related to daily experiences, which provided a more attentive and critical view on these aspects.

Keywords: Gamebook; Critical Mathematical Education; Mathematics teaching.

\section{INTRODUÇÃO}

De um modo geral, esperamos que os professores das mais diferentes áreas interajam com seus alunos com o objetivo de fornecer-lhes ferramentas que possam ajudá-los a compreender, refletir e intervir no mundo em que vivem. Tornando-os agentes com poder de interpretar e agir sobre esse mundo, podendo, inclusive, interferir na sua própria perspectiva de futuro.

Entendemos também que é necessário e urgente que os alunos sejam con vidados pelos seus professores a se envolverem em discussões sobre os diversos "usos" da matemática fora da esfera educacional, tomando certo distanciamento crítico dos conteúdos. E para fazer esse convite, os professores podem se apoiar em diferentes perspectivas e estratégias metodologias de ensino, e ainda fazer uso de diversos recursos didático-pedagógicos (em meio físico ou digital), acenando aos alunos para que embarquem em um cenário propício à investigação e à aprendizagem.

Portanto, este relato tem como objetivo apresentar e avaliar o livro-jogo (uma aventura solo ou história interativa) como um recurso didático-pedagógico para o ensino e aprendizagem de matemática com abordagem da Educação Matemática Crítica (EMC).

Através de um livro-jogo, foi apresentada uma história (interativa) que problematizou questões do cotidiano e da sociedade voltad as à matemática, propiciando o desenvolvimento de conteúdos curriculares que puderam partir dessa temática, compreendendo-o como um convite a um ou múltiplos cenários para investigação e

Recebido em: 30 /04/ 2020

Aceito em: 19/1 1/2020 
Edição Especial: XVI Encontro sobre Investigação na Escola - EIE

assim verificar as contribuições do livro-jogo para a aprendizagem de matemática através dos cenários para investigação.

Trazemos também para esse diálogo as ideias de Freire (1996) assim como teóricos que ajudaram a desenhar o pano de fundo temático específico do ensino de matemática ao qual a proposta está inserida trazemos, em especial, Milani (2020) e Skovsmose (2000, 2001, 2014).

O Livro-jogo apresenta-se como uma variante do Role-Playing Game (RPG), através de Saldanha e Batista (2009) e por Fernandes (2017). E para problematizar a importância dos jogos na Educação Matemática nos embasamos em Muniz (2010).

Os resultados relatados, através da coleta e análise de dados a partir da aplicação do livro-jogo, demonstrou que a proposta, também conhecido como aventura solo, trouxe elementos que podem instigar de forma dinâmica e interessante a busca de conhecimentos e informações importantes de uma determinada área ou conteúdo e ainda ser um bom recurso didático-pedagógico na apresentação e desenvolvimento de cenários para investigação, possibilitando ir muito além da história apresentada.

\section{CONTEXTO E DETALHAMENTO DAS ATIVIDADE}

Para estimular a predisposição dos alunos ao aprendizado, fazendo com que es s a aprendizagem seja significativa, foi criado um livro-jogo e aplicado em u ma turma do sétimo ano do ensino fundamental de uma escola da rede pública municipal no município de Igrejinha no Estado do Rio Grande do Sul.

A turma com a qual foi aplicada a leitura do livro-jogo era composta por vinte (20) alunos, sendo oito (8) meninas e doze (12) meninos, com idades entre onze e treze anos. A escola fica num bairro um tanto afastado do centro da cidade e atende também alunos da zona rural.

Para a criação do livro-jogo referido no presente trabalho, foi usada a plataforma on-line Twine 2 (Figura 1). Esta plataforma é de uso gratuito e possibilita a criação da história de forma dinâmica, onde se pode visualizar, como num mapa, todos os possíveis caminhos que vão sendo apresentados, havendo a possibilidade de serem feitas alterações a qualquer momento da criação. Além disso há a possibilidade de serem inseridas figuras e vídeos dentro da história com comandos específicos disponíveis e com orientações fornecidas na própria plataforma. 
Edição Especial: XVI Encontro sobre Investigação na Escola - EIE

ISSN: $2595-4520$

Vol. 4, n. 2. 2021

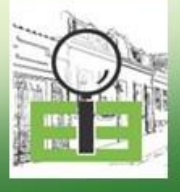

É importante destacar que o leitor-jogador não tem acesso a essa parte da plataforma, conseguindo acessar, ler e jogar somente a história criada.

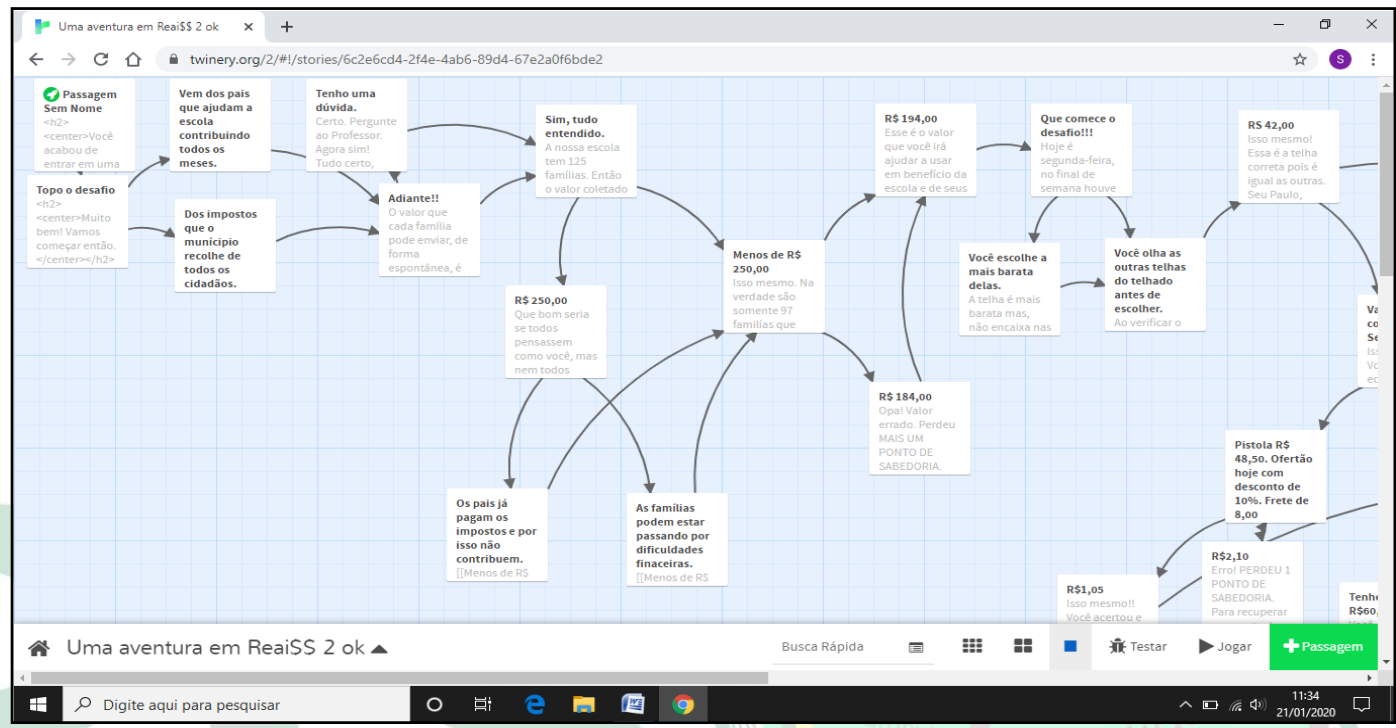

Figura 1 - Visão geral da cria ção do livro-jogo na plataforma Twine 2. Fonte - Elaborado pelo autor na plataforma Twine 2.

A seguir, tem-se uma parte da história criada na plataforma (Figura 2) onde pode se perceber a existência de duas opções de caminho que o leitor-jogador pode e scolher de acordo com suas convicções e enten dimentos.

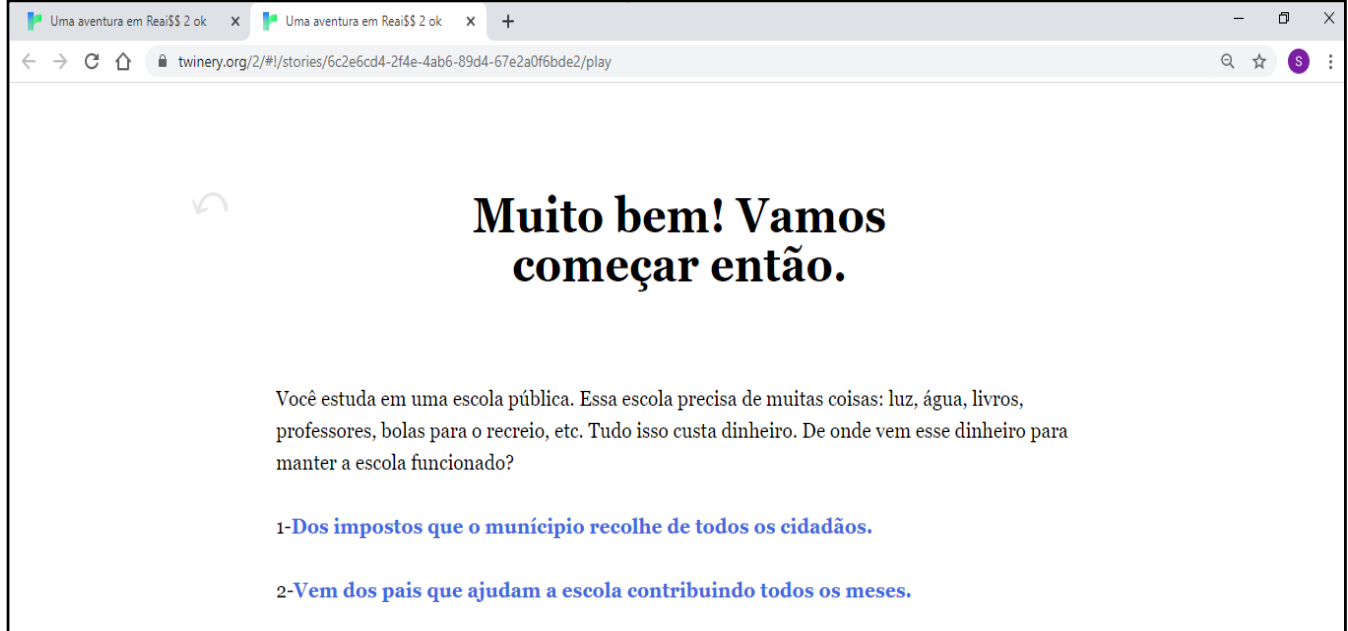

Figura 2 - Parte da História do livro-jogo na plataforma Twine 2. Fonte - Elaborado pelo autor na plataforma Twine 2. 
A história do livro-jogo teve como título "Uma aventura em Reai\$” em alusão a temática abordada, envolvendo as problemáticas enfrentadas no dia a dia da escola. No enredo, o personagem principal (aluno leitor-jogador) supostamente teria sido escolhido pela direção da escola para auxiliar a gerir um recurso oriundo da contribuição das famílias com a Associação de Pais e Mestres (essa contribuição espontânea existe realmente na escola em questão e os alunos têm ciência da finalidade destes recursos ). No decorrer da história o leitor-jogador vai se deparando com situações onde, como por exemplo, precisa decidir a compra ou não de materiais, fazer escolha entre prioridades, tomar decisão em relação a um fato, além de perceber situações reais que ocorrem na escola que normalmente os alunos não tem acesso.

Algumas das situações apresentadas ao leitor foram elaboradas de forma que se tivesse mais de uma alternativa de solução satisfatória, com o intuito de possibilitar ao aluno o entendimento de que um mesmo problema pode ser resolvido de forma variada ou até não ter resposta, objetivando criar um cenário para investigação, que visou levar o aluno ao milieu 4 ou 6 segundo Skovsmose (2014).

Para discutir os cenários para investigação, Skovsmose (2014) apresenta seis ambientes de aprendizagem aos quais chama de "milieus" (formas de conduzir o estudo da matemática), conforme a Tabela 1 . Nota-se que quanto mais aproxima-se do milieu 6, mais distante se está do paradigma do exercício.

Tabela 1 - milieus

\begin{tabular}{|c|c|c|}
\hline Referências à matemática pura & Paradigma doexercício & Cenário para investigação \\
\hline Referências a umasemirrealidade & $(1)$ & $(2)$ \\
\hline Referências à vida real & $(3)$ & (4) \\
\hline
\end{tabular}

Fonte - Boito Filho a pud Skovsmose (2014,p.63)

Como a escola dispunha de rede $W i-F i$ para alunos e muitos deles possuíam smartfone, foi organizado um grupo de WhatsApp pelo qual disponibilizou-se o link de acesso ao livro-jogo. Os alunos reuniram-se em duplas para realizar a leitura vis to que nem todos os alunos tinham smartfone e para que pudessem trocar ideias nas decisões durante a leitura.

As questões abordadas no livro-jogo faziam referência à Matemática e de co mo melhor administrar certa renda destinada à escola. As questões que exigiam conhecimentos matemáticos eram problemas em que aplicariam seus conhecimentos

Recebido em: 30 /04/ 2020

Aceito em: 19/11/2020 
Edição Especial: XVI Encontro sobre Investigação na Escola - EIE

prévios para a resolução, não havendo a apresentação de novas aprendizagens matemáticas, bastando interpretar a situação e resolvê-la, isto é, as escolhas certas a serem tomadas para prosseguir na aventura dependiam de suas habilidades de leitura e de conhecimentos matemáticos adquiridos até então (Figura 3). Por sua vez, as questões que abordariam mais especificamente um viés crítico, como em certa medida problematiza a EMC, estavam intercaladas com as demais, fazendo-se necessário o debate entre a dupla objetivando a melhor decisão.

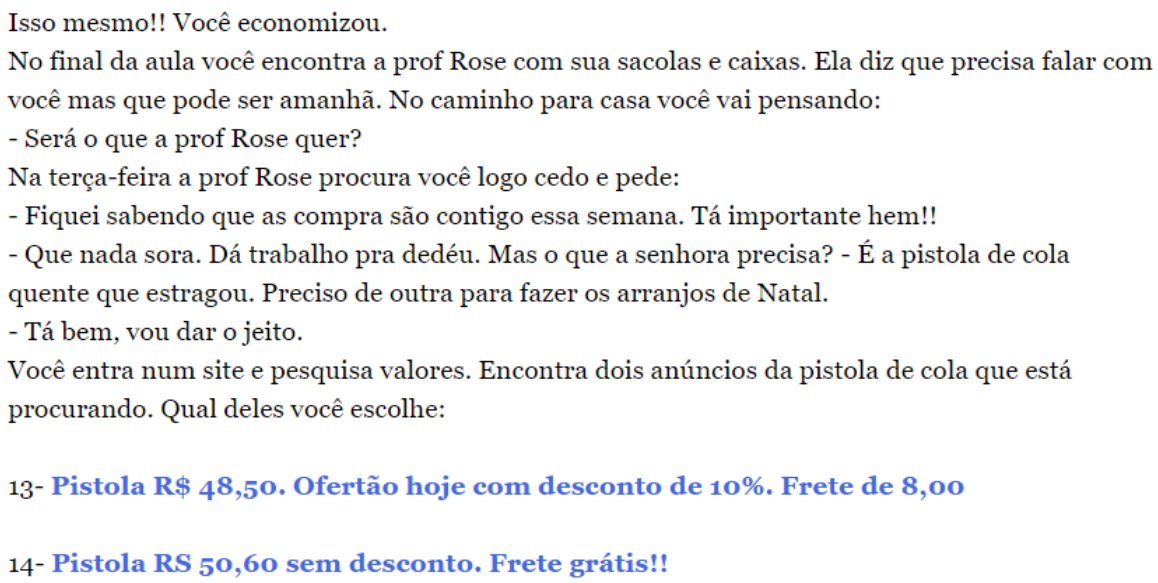

Figura 3 - Questão sobre cálculo de porcentagem de desconto. Fonte - Ela borado pelo a utor na plataforma Twine 2 .

Como instrumentos para coleta de dados foram elaborados e aplicados uma ficha de acompanhamento da leitura e um questionário. A ficha de acompanhamento da leitura (Tabela 2) era numerada de 1 (um) a 28 (vinte e oito), contemplando tod as as possíveis escolhas a serem feitas durante a leitura. Foram orientados a justificar na ficha as motivações que a dupla usou para a escolha, com o objetivo de registrar os entendimentos e aprendizagens que tiveram em relação às situações abordadas na história para evidenciar os conhecimentos de Matemática e de EMC.

Tabela 2 - Cabeçalho da ficha de acompanhamento da leitura.

\begin{tabular}{|c|c|}
\hline $\begin{array}{c}\text { Marcarx } \\
\text { nas suas } \\
\text { escolhas }\end{array}$ & Justificar porque escolheu esse caminho, mostrar cálculos feitos se houver. \\
\hline 1 & \\
\hline
\end{tabular}

Recebido em: 30 /04/ 2020

Aceito em: 19/11/2020 
Edição Especial: XVI Encontro sobre Investigação na Escola - EIE

\begin{tabular}{|l|l|}
\hline 2 & \\
\hline 3 & \\
\hline$\cdots$ & \\
\hline 28 & \\
\hline
\end{tabular}

Fonte - Elaborado pelo a utor.

Após a leitura, receberiam um questionário avaliativo (Quadro 1), onde deveriam responder com suas percepções sobre o livro-jogo e seus sentimentos em relação as situações abordadas na história. O questionário era composto por 7 (sete) questões, destas, 5(cinco) eram de múltipla escolha e contavam com espaço para comentários e 2(duas) eram de resposta discursiva.

Quadro 1 -Questionário a valiativo sobre o livro-jogo.

Questionário
1)Você gostou da história do Livro-jogo? ( ) Sim, gostei. ( ) Não gostei. ( ) Razoável.
Comentário:
2)Você considerou as questões fáceis ou difíceis? ( ) Difíceis. ( ) Ra zoáveis. ( ) Fáceis.
Comentário:
3)Qual situação enfrentada você achou mais desafiante? Por quê?
4)O decorrer da leitura do livro-jogo foi dinâmico e de fácil entendimento? ( )Sim ( )Não
)Razoável
5)Você indicaria o livro-jogo para um colega? ( ) Talvez. () Não. ( ) Sim
$\quad$ Comentário
6)Você gostaria de aprender ou estudar outros conteúdos dessa forma? ( ) Sim. () Não. Justifique
sua resposta.
7)Houve mais alguma coisa que você aprendeu, pensou ou fez de interessante além da
aprendizagem de Matemática? Conte o que foi e por que isso chamou sua atenção.

Fonte - Elaborado pelo autor.

\section{ANÁLISE E DISCUSSÃO DO RELATO}

Os resultados que seguem demonstram que o livro-jogo pode ser um excelente material didático-pedagógico para a apresentação de temáticas da EMC, podendo estimular os alunos a aplicar conhecimentos prévios, possibilitan do a busca por novos conhecimentos, não só matemáticos, além de estimular a leitura de forma mais interessante e divertida. Portanto, a análise não tem como foco categorizar os erros dos alunos nas questões de matemática, mas verificar se o livro-jogo, como uma ferramenta 
Edição Especial: XVI Encontro sobre Investigação na Escola - EIE

pedagógica envolve os alunos e pode de fato ser um objeto potencializador para criar cenário para investigação.

Portanto, iniciaremos a análise a partir da ficha de acompanhamento da leitura, que foi apresentada juntamente com o livro-jogo. As duplas de alunos seguiram a orientação de fazer os registros dos cálculos apresentados durante o desenvolvimento da história e de suas justificativas quanto às escolhas e decisões que tomaram ao avançar na aventura proposta, o que possibilitou obter material para evidenciar os conhecimentos matemáticos dos alunos assim como a capacidade de tomarem decisões acerca de escolhas envolvendo o uso do dinheiro da escola (Figura 4).
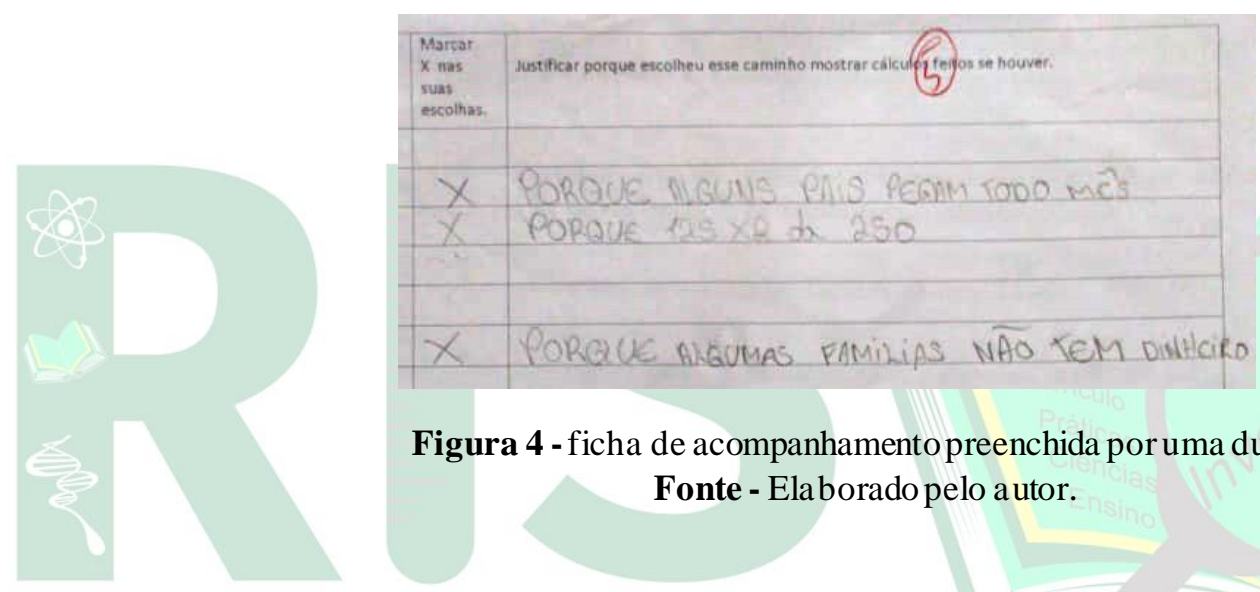

Figura 4 - ficha de acompanhamento preenchida por uma dupla.

Fonte - Elaborado pelo a utor.

A primeira questão da história analisada na ficha se referia à origem dos recursos para manter a escola funcionado. Como vimos, a questão traz os elementos que são entendidos por Skovsmose (2000) como cenários de investigação, pois convida os alunos a fazerem questionamentos e buscarem explicações do porquê algumas famílias contribuíam e outras não, envolvendo-se em um processo de exploração em busca de respostas, constituindo um novo ambiente de aprendizagem (Quadro 2).

Quadro 2 - Justificativas para a não contribuição espontânea.

“As famílias podem não ter dinheiro todo mês."-dupla D7

"Porque muitas famílias trabalham mas não tem um salário bom.”-dupla D10

"Por que como sabemos algumas pessoas não têm emprego entre outras coisas." -du pla D3

“Por que alguns pais podem estar desempregados."-dupla D5

Fonte - Elaborado pelo autor.

Recebido em: 30 /04/ 2020

Aceito em: $19 / 11 / 2020$ 
A segunda questão analisada tratava do número de famílias que têm seus filhos na escola em relação aos recursos financeiros recolhidos de forma espontânea pela Associação de Pais e Mestres. Todos as duplas acertaram o cálculo para determinar esse valor, demonstrando que os alunos estão acostumados a resolver problemas onde o professor fornece dados e espera uma resposta correta. Nenhuma dupla deu-se conta de que a contribuição sendo espontânea poderia ocorrer que nem todos contribuís sem, o que já havia sido comprovado anteriormente com a direção da escola. Ao terem a informação de que nem todas as famílias contribuíam, trouxeram as possíveis justificativas.

Sabemos que muitas dessas observações são baseadas nas experiências dos próprios alunos, sendo a realidade da maioria dos estudantes da escola pública. Fazer pensar sobre a sua realidade é papel da educação. Como vemos, na aula de matemática também há espaço para desenvolver a criticidade nos alunos. Uma “simples" questão fez com os alunos pensassem e tentassem compreender o contexto social no qual estão inseridos onde, nesse contexto, parecesse justo que algumas famílias, talvez por não terem um salário bom, poderiam não contribuir sem que houvesse qualquer consequência.

A análise dos resultados obtidos pela ficha de acompanhamento da leitura mostrou que o livro-jogo cumpriu com o papel de educativo, de modo que a maioria dos alunos respondeu corretamente as questões de cunho meramente matemático. Além disso, foi possível perceber através dos posicionamentos apresentados em relação a questões sociais e econômicas, que é uma ferramenta que possibilita ultrapassar os limites da sala de aula convidando o aluno a refletir e se informar sobre problemas do seu dia-a-dia, de proporcionar um espaço para questionar a realidade social, econômica e política do meio em que vivem, o que são preceitos da EMC.

Quanto às questões apresentadas (conforme Figura 05 do capítulo anterior), estas foram propostas aos alunos para avaliar a utilização do livro-jogo como instrumento didático-pedagógico de ensino de matemática, de modo que os alunos pudessem apontar suas percepções, gostos e possíveis dificuldades encontradas na leitura ou, ainda, relatar se o método era estimulante ao aprendizado. Assim, a informação quantitativa será descritiva e nos quadros serão apresentados exemplos de relatos com o intuito de ilustrar cada questão.

Observou-se, então, para a primeira questão que a maioria significativa, aproximadamente $90 \%$ dos alunos, gostou da história do livro-jogo (Quadro 3). Isso representou o entusiasmo com que aceitaram e fizeram a leitura ainda mais estimulados 
Edição Especial: XVI Encontro sobre Investigação na Escola - EIE

pelo meio tecnológico, em que alguns alunos ficaram aproximadamente 1(uma) hora realizando a leitura, indo e vindo no texto, chegando finais prévios indesejados e retornado até alcançar o final desejado. Dado este que não surpreendeu pela característica da atividade, que por ser um jogo, trazendo elementos desafiadores e envolventes, viria como uma possível ferramenta de incentivo à leitura. Alguns comentários dos alunos demonstram seu gosto pela história do livro-jogo. Não houve alunos que optaram por "não gostei".

Quadro3 - Comentários sobre a primeira questão referente ao gosto pela história.

\begin{tabular}{|l|c|c|l|}
\hline \multicolumn{1}{|c|}{ Sim, gostei. } & Não gostei. & & \multicolumn{1}{c|}{ Razoável } \\
\hline $\begin{array}{l}\text { "Adorei,pois a cheidiferente } \\
\text { e interativo."-aluno A2 } \\
\text { "Muito legalporpensar em } \\
\begin{array}{l}\text { coisas que a contecem de } \\
\text { verdade."-aluno A12 }\end{array}\end{array}$ & - & $\begin{array}{l}\text { "Porque tem pegadinhas."- } \\
\text { aluno A7 } \\
\text { "Fiquei com dúvida para } \\
\text { fazera escolha certa."-alu no } \\
\text { A10 }\end{array}$ \\
\hline
\end{tabular}

Fonte - Elaborado pelo autor.

Em relação à segunda questão (Quadro 04), referente às dificuldades nos questionamentos da história, e um número significativo, $65 \%$ dos alunos, considerou as questões como difíceis ou de razoável dificuldade devido a serem questões que fu giam do paradigma do exercício, que para Skovsmose (2014) servem para manter as perguntas e também as respostas dos alunos num estado previsível. As questões desafiadoras requerem respostas criativas com as quais os alunos não estão habitu ados, na maioria das vezes, a lidarem em sala de aula.

Quadro 4 -Comentários sobre a segundaquestão referenteà dificuldadenos questionamentos na leitura da história.

\begin{tabular}{|l|l|l|}
\hline Fáceis. & Difíceis. & Razoáveis \\
\hline
\end{tabular}


Edição Especial: XVI Encontro sobre Investigação na Escola - EIE

ISSN: 2595-4520 Vol. 4, n. 2. 2021

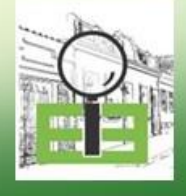

\begin{tabular}{|c|c|c|}
\hline & $\begin{array}{l}\text { "Tinha que pensar muito." - } \\
\text { aluno A5 } \\
\text { "Algumas fiquei indeciso." - } \\
\text { aluno A1 }\end{array}$ & $\begin{array}{l}\text { "Algumas mais difíceis que as } \\
\text { outras."-a luno A1 } 1 \\
\text { "Tinha pegadinhas nas } \\
\text { perguntas."-aluno A15 }\end{array}$ \\
\hline
\end{tabular}

Fonte - Elaborado pelo autor.

Sobre a leitura do livro-jogo ser dinâmica e de fácil entendimento, $90 \%$ dos alunos consideraram que sim, visto que o enredo era interessante e os personagens eram conhecidos deles na escola. Já $10 \%$ relataram alguma dificuldade na leitura, como mostra o Quadro 5.

Quadro5 -Comentários sobre a quarta questão referente a leitura do livro-jogo ser dinâmica e de fácil entendimento.

\begin{tabular}{|l|c|l|}
\hline \multicolumn{1}{|c|}{ Sim. } & \multicolumn{1}{|c|}{ Não. } & \multicolumn{1}{c|}{ Razoável. } \\
\hline $\begin{array}{l}\text { "Achei legal, poderia ter mais nas } \\
\text { aulas."-aluno A8 } \\
\text { "Entendi bem fá cil porque era tudo } \\
\text { bem explicado."-aluno A10 }\end{array}$ & - & $\begin{array}{l}\text { "Tive dúvidas para entender algumas } \\
\text { partes."-aluno A14 } \\
\text { "Acheia história muito longa."-aluno } \\
\text { A19 }\end{array}$ \\
\hline
\end{tabular}

Fonte - Elaborado pelo autor.

Ao serem questionados se gostariam de aprender ou estudar outros conteúdos utilizando o livro-jogo (Quadro 6), todos os alunos responderam que sim, demonstrando que o livro-jogo pode tornar atrativa e prazerosa a aprendizagem trazendo aos alu nos o desejo de conhecer. Também justificaram suas respostas conforme os exemplos citad os no quadro a seguir.

Quadro 6 - Comentários sobre a sexta questão referente a o desejo de u sar o livro-jogo para estudar outros conteúdos.

\begin{tabular}{|l|}
\hline "É uma forma divertida de aprender eu iria ficar mais inteligente." -a luno A16 \\
\hline "Porque no livro temos que raciocinar."-a luno A1 1 \\
\hline "Claro, vocêa caba interagindo mais com a questão."-aluno A8 \\
\hline "Porque a aula foibem legale divertida."-aluno A1 \\
\hline "Pois é ma is divertido, o conteúdo de uma forma diferente, foi bem mais interessante com o livro-jogo." \\
-aluno A2 \\
\hline
\end{tabular}

Fonte - Elaborado pelo autor.

A relação dos alunos com o livro-jogo foi além da esperada ao relatarem outras aprendizagens que foram possíveis na percepção deles, o que demonstra o quanto

Recebido em: 30 /04/ 2020

Aceito em: 19/11/2020 
realmente esta ferramenta pedagógica pode ser levada em consideração e utilizada para transpor a sala de aula, proporcionando o trabalho cooperativo, o compartilhamento de ideias, poder de argumentação que são capacidades extremamente necessárias nos dias atuais e em todas as atividades humanas. Ao serem questionados se aprenderam mais alguma coisa além da aprendizagem de matemática, relataram o que segue no Quadro 7.

Quadro 7 -Comentários sobre a sétima questão referente a outras a prendizagens adquiridas na leitura do livro-jogo.

\begin{tabular}{|l|}
\hline “Alguma coisas em promoçãonas lojas não valem a pena."- aluno A16 \\
\hline “Aprendi que as vezes uma coisa mais barata pode não ser tão boa a qualidadee a gente acaba ga stand o \\
mais."- a luno A13 \\
\hline “Que pode ter mais de uma resposta, sem ser a quela certinha."-aluno A11 \\
\hline "Aprendia pensar mais para usaro dinheiro e ver qualidade e preço."-aluno A10 \\
\hline "Com a leitura consegui venceros desafios."-aluno A4 \\
\hline
\end{tabular}

Fonte - Elaborado pelo autor.

Em relação ao questionário, onde os alunos responderam sobre suas expectativas, dificuldades e sentimentos, pôde-se identificar que o livro-jogo foi do agrado de to dos os alunos, por terem demonstrado satisfação ao realizar a leitura e vencer os desafios propostos e, ainda, percebê-lo como um instrumento para abordagem de outros assuntos.

\section{CONSIDERAÇÕES FINAIS}

Ao final da análise dos resultados foi possível apresentar um parecer favorável ao uso do livro-jogo como recurso didático-pedagógico para abordar o ensino da Matemática e da Educação Matemática Crítica. Os alunos sentiram-se estimulados pela dinâmica da história quanto pela apresentação do livro-jogo na forma digital.

A proposta do livro-jogo levou os alunos a sentirem-se desafiados a ler e, lendo, aprenderem mais sobre os temas abordados no decorrer da aventura. Conseguiram obter informações que podem levá-los a compreender melhor a realidade que os cerca além de promover a integração e o compartilhamento de conhecimentos enquanto é jogado. A leitura serviu para reforçar conteúdos de Matemática já trabalhados em sala de aula, demonstrando que o livro-jogo pode agir como auxiliar ao estudo e como uma possibilidade de avaliação de conhecimentos.

Recebido em: 30 /04/ 2020

Aceito em: 19/11/2020 
Edição Especial: XVI Encontro sobre Investigação na Escola - EIE

Em conclusão, pelo material analisado e observações realizadas, é possív el dizer que o livro-jogo contribuiu significativamente para ampliar nos alunos o desejo de saber e construir uma "nova" forma de aprender, estimulando a criatividade e a criticidade.

\section{REFERÊNCIAS}

SKOVSMOSE, O. Cenários para Investigação. Rio Claro, SP: Bolema, 2000.

SKOVSMOSE, O. Educação matemática crítica: A questão da democracia. Campinas, SP: Papirus, 2001.

SKOVSMOSE, O. Um convite à educação matemática crítica. Campinas: Papirus, 2014.

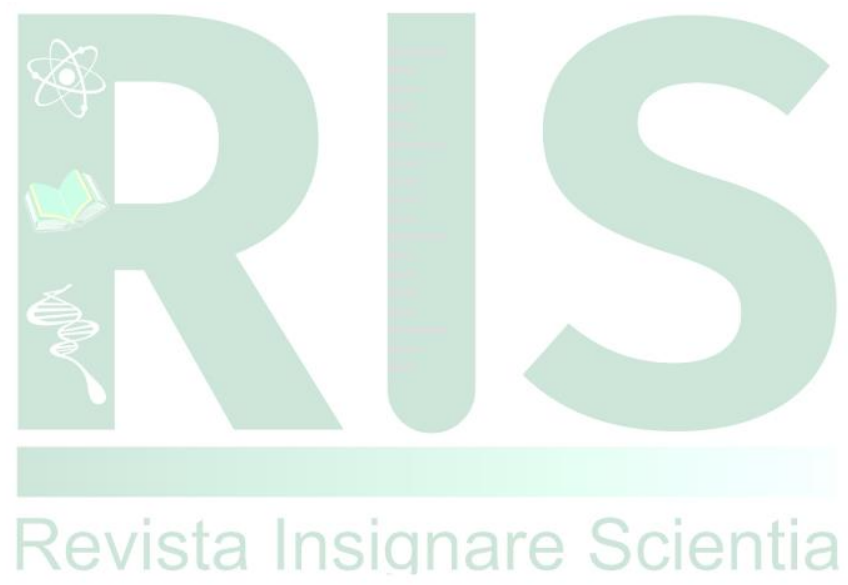

